\title{
sciendo
}

\section{Possibilities to quantify the road traffic on the national road network and motorways in Romania}

\author{
Robert-Adrian SANDU \\ Universitatea Tehnică din București, Facultatea CFDP, Romania \\ robert.sandu@cestrin.ro \\ Carmen RĂCĂNEL \\ Universitatea Tehnică din București, Facultatea CFDP, Romania \\ carmen.racanel@utcb.ro \\ Daniela-Ioana MANEA \\ The Bucharest University of Economic Studies, Romania \\ daniela.manea@csie.ase.ro \\ Mihaela MIHAI \\ The Bucharest University of Economic Studies, Romania \\ mihaela.mihai@csie.ase.ro
}

\begin{abstract}
As a result of the economic crisis of 2009-2010, the road traffic on the national road network, for the period 2011-2014, decreased considerably. Thus, the evolution coefficients, for the period 20202025 , registered a trend of decrease in road traffic.

Based on the analysis of the results of the automatic traffic records, it was found that the average daily average traffic increased by about 4.7\% in 2016 compared to 2015 (the year of the last general circulation census) and is in continuous growth, one of the reasons being removal of car registration tax. In 2015, for the development of evolution coefficients and the rates of evolution of traffic on the national road network, the linear regression method was used which took into account both the evolution of road traffic reported in 1995, 2000, 2005 and 2010, as well as the evolution of road traffic on the traffic counters network for the period 2010-2015.

The paper analyzes aspects of the efficiency of the method used until the present and the need to develop coefficients and rates of evolution based on more complex methods, based on several economic and social indicators, including the projected evolution of GDP.
\end{abstract}

Keywords: interurban traffic detection systems; traffic counters; forecast of traffic evolution; coefficients of evolution of road traffic; traffic modeling.

\section{Introduction}

One of the main components of economic activity, with undesirable effects on the environment, is transportation. A sustainable economy involves optimizing urban planning based on transport studies by modeling and simulating traffic. Obviously, a strong road network can lead to major benefits for a country's economic development, a reliable road network being vital to any country specifically for developing countries.

Based on transport demand, driven by economic activity and transport prices, and on the development of road infrastructure, the volume of road traffic is an important variable in 
transport simulation and planning applications. Thus, road traffic theories attempt to describe, based on a mathematical model, interactions between vehicles or between them and infrastructure operators. Most of these studies focus on explaining and exploring as closely as possible the relationships that are formed between the variables of interest in traffic theory by establishing the mathematical equations of the model.

Most of these studies focus on explaining and exploring as closely as possible the connections that are formed between the variables of interest in traffic theory by establishing the mathematical equations of the model.

\section{Literature review}

The issue of road traffic is a very stringent one, as evidenced by the numerous scientific articles published in the field of transport as well as the innovative achievements in the industry. In this sense, the automotive industry through the major machine-building companies has implemented the fruit of scientific research through numerous achievements, which have facilitated and streamlined the road traffic, increased the level of safety of the participants, having a favorable impact on the environment.

The first scientific studies in the field of road transport originated in the 1930s, with the development of econometrics as a science, building the first traffic patterns, used and developed at present.

According to the Motorway Working Group Report ${ }^{1}$ carried out by the experts of the European Commission, after 1993 an economic space without internal frontiers and the single market represent a reality. Initially, it was assumed that trans-European transport networks would optimize traffic beyond the borders of the twelve countries in the EU at that time. Initially, it was assumed that Trans-European Transport Networks (TEN-T) would optimize traffic beyond the borders of the twelve countries in the EU at that time. In the long run, the development of today's European road network was being pursued. It should be noted that this report highlighted the negative impact on the safety of the network generated by the increase in traffic volume and highlighted the value of the development of intercommunity anti-collision systems. At the same time, the forecasted growth of road traffic for the next 20-25 years raised questions regarding air pollution control and collateral effects.

In order to solve the forecast of traffic on the motorway, models based on historical data, time series, neural networks and using the using a two-stage least squared, 2SLS regression method (Taylor and Miller, 2003) and regression models nonparametric (Ripley, 1999).

The development of the public road network is determined by the inherent benefits of a road network, both economically integrated as well as safety. Thus, in 2017, Dolombyan ${ }^{2}$ presents in his paper a traffic forecasting model for a road section based on a transport information model.

The econometric models for traffic forecasting on transport networks were the base for the estimated traffic on the motorways in Croatia (Pupavac, 2014). In both models,

\footnotetext{
1 Commission of the European Communities, Directorate-General for Transport. (1993). Trans-European Networks. Towards a Master Plan for the Road Network and Road Traffic? Motorway Working Group Report, Brussels, Luxembourg.

${ }^{2}$ Dolombyan A.V., Kocherga E.V., Semchugova E., Negrov N. (2017). Traffic forecasting model for a road section. Transportation Research Procedia, 20, 159-165
} 
besides the factorial variables: petrol price, number of registered personal vehicles, number of arrivals, etc. Gross Domestic Product (GDP) was considered as a variable that significantly influences traffic on Croatian motorways.

In Romania, the SUBSTANTIATION STUDY for Târgu Neamţ - Iaşi Motorway (2018) and Ploiești - Braşov motorway, carried out by the National Commission for Strategy and Prognosis (CNSP), are based on data provided by the National Institute of Statistics (NIS), the results of the National Circulation Census carried out by CESTRIN in 2010 and 2015, based on the 2012 and 2015 Origin-Destination (OD) data, as well as passenger and coach passenger numbers calculated from the AECOM (Architecture, Engineering, Construction, Operation and Management). In order to estimate the coefficients of traffic evolution on the national road network and motorways in our country, regression models were used.

\section{The evolution of road traffic in Romania}

\section{Traffic Census results from 2015}

The public road network on which the traffic census was conducted in 2015 covered 46687 $\mathrm{km}$ of national, county and communal roads, in which 3193 census posts were located (Table no. 1).

Table no. 1- The public road network reviewed in 2015

\begin{tabular}{|l|r|r|r|r|}
\hline \multirow{2}{*}{ Category road } & \multirow{2}{*}{$\begin{array}{c}\text { Number of census } \\
\text { posts }\end{array}$} & \multicolumn{2}{|c|}{ Length reviewed } & \multirow{2}{*}{$\begin{array}{c}\text { AADT } \\
\text { (Vehicles/ 24 hours) }\end{array}$} \\
\cline { 3 - 4 } & 959 & $16063^{*}$ & 100 & 5498 \\
\hline National roads & 2100 & $29350^{*}$ & 83 & 982 \\
\hline County roads & 134 & 1274 & 4 & 709 \\
\hline Communal roads & & & 40 network & \\
\hline
\end{tabular}

* the length does not include city crossings source: CESTRIN

\section{Road traffic evolution during the 1990-2015}

From the analysis of the traffic evolution for the period 1990-2015, on the public roads networks (Table no. 2) we observe an increase of approximately $70,69 \%$ of the traffic on the national roads and a decrease of almost $8,14 \%$ for the county ones. Compared with the previous traffic census data (2010), the same trend is observed for the evolution of traffic: if for national roads we see an increase of $1.05 \%$ for the county ones we have a decrease of $4.66 \%$.

Table no. 2- Road traffic evolution during the 1990-2015 period across the national road network

\begin{tabular}{|c|c|c|c|c|c|c|c|c|c|c|c|c|}
\hline \multirow{3}{*}{$\begin{array}{l}\text { Category } \\
\text { road }\end{array}$} & \multicolumn{12}{|c|}{ AADT (Vehicles/ 24 hours) } \\
\hline & \multicolumn{6}{|c|}{ National roads } & \multicolumn{6}{|c|}{ County roads } \\
\hline & 1990 & 1995 & 2000 & 2005 & 2010 & 2015 & 1990 & 1995 & 2000 & 2005 & 2010 & 2015 \\
\hline \begin{tabular}{|l|} 
Total \\
vehicles
\end{tabular} & 3221 & 3857 & 3776 & 4150 & 5441 & 5498 & 1069 & 1175 & 1008 & 962 & 1030 & 982 \\
\hline
\end{tabular}

source: CESTRIN

The evolution of freight and passenger transport after 1989 was strongly influenced by the evolution of our country's economic situation, mainly reflected by the GDP indicator.

Of the transport sectors, road freight and passenger transport has, after 1989, the highest share in transport, a situation similar to the developed countries in Europe. The 
evolution of traffic on the interurban public road network between 1990 and 2015 was of a sinuous character, this situation being determined mainly by the evolution of the economic situation, but also by the evolution of the motor vehicle fleet and its utilization rate.

Regression of traffic between 1995-2000 and 2010-2015 was temporary and caused by the international economic downturn. Under the conditions of a positive evolution of the economy, after 2015 there is a significant increase in traffic, with an even more pronounced increase in the following period.

\section{Road traffic forecast in Romania}

\section{Road traffic forecast for the period 2015-2040}

For the estimation of the evolution of traffic for the period 2015-2040, average coefficients of evolution of road traffic by country, by vehicle groups, were developed in three hypotheses of evolution: maximum - optimistic, medium - probable and minimal - pessimistic.

Based on the analysis of the traffic evolution on the public road network in the period 1995-2010, regarding the data obtained from the traffic censuses, and from the network of traffic meters for the period 2011-2017, a differentiation of specific coefficients was made by road category: European national roads, main national roads, secondary national roads, county roads and communal roads was made in the assumed average (probable) evolution of traffic.

The traffic evolution forecast for the years 2020, 2025, 2030, 2035 and 2040 was determined using the average (probable) evolution of traffic. Thus, prospective traffic by vehicle groups was determined for each census category by road category.

On the whole national and county road network the evolution of traffic by 2015 and the forecast until 2040 is presented in the previous figure. This forecast forecasts an increase of 1.20 times the traffic, in the period 2015-2025, on the national road network and 1.13 times on the county road network, and for the period $2015-2040$ is estimated on the national road network an increase in the traffic of 2, 25 times and 2.12 times on the county road network.

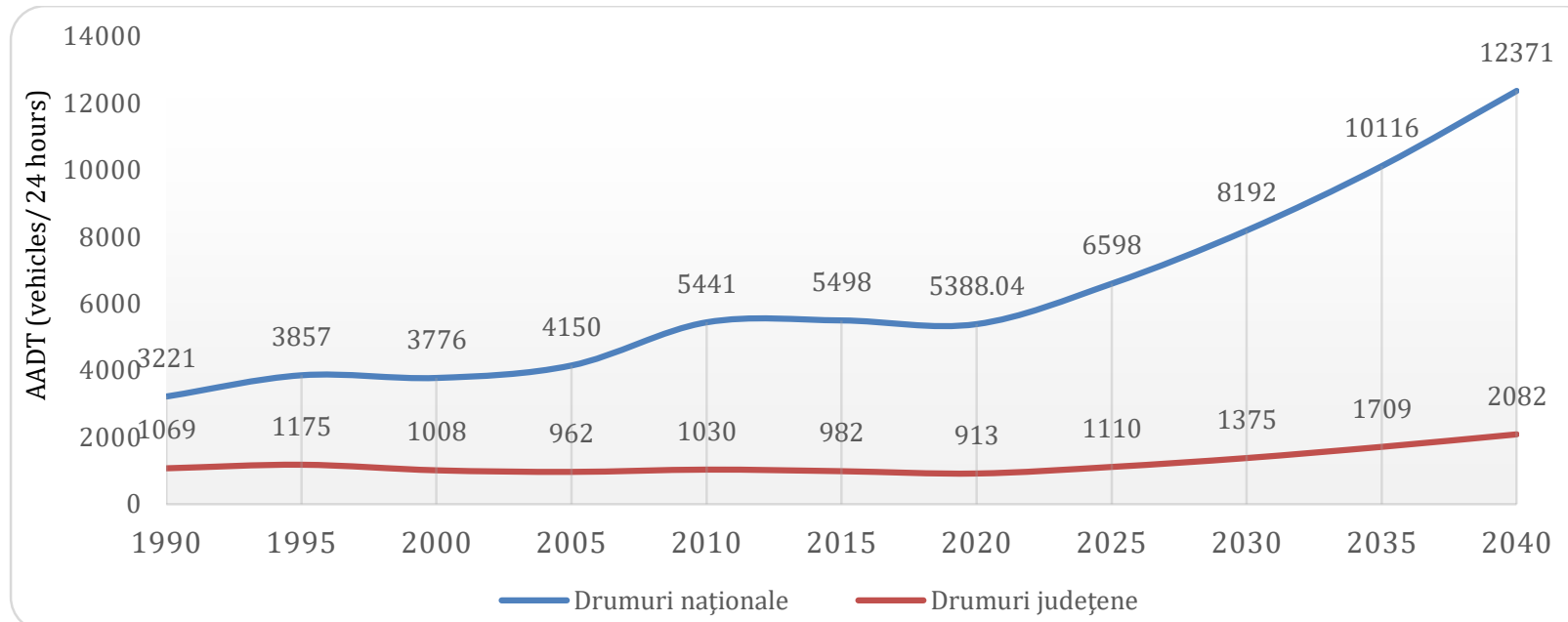

Figure no. 1 - The real evolution of the AADT (vehicles/ 24 hours) in the period 19902015, according to the results of the traffic censuses and the predicted evolution of the AADT for the period 2015-2040 on the public roads source: CESTRIN 
Based on the analysis of the annual average daily traffic (AADT) data obtained through the processing of the 2015 census records and the prognosis of traffic evolution on the national road network obtained with the growth coefficients developed in 2011, it is easy to see that it is not obtained a confirmation of short-term prognosis even when using pessimistic coefficients. This is explained, on the one hand, by the effects of the economic crisis in 2009-2011 and, on the other hand, by the simplicity of the development model of the evolution coefficients used.

Table no. 3 - Traffic Census report 2015 / forecast for year 2015 Annual Average Daily Traffic (AADT)

\begin{tabular}{|c|c|c|c|c|c|c|}
\hline $\begin{array}{c}\text { Year and Census Report } \\
\text { / Forecast }\end{array}$ & Cars & $\begin{array}{c}\text { Minibuses } \\
\text { with max } \\
8+1 \text { seats }\end{array}$ & Trucks & TIR & Buses & $\begin{array}{c}\text { Total } \\
\text { vehicles }\end{array}$ \\
\hline Traffic census 2015 & 3574 & 196 & 350 & 530 & 158 & 5498 \\
\hline Forecast 2015* & 4613 & 294 & 444 & 534 & 131 & 6766 \\
\hline R2015/P2015*\% & 0,77 & 0,67 & 0,79 & 0,99 & 1,21 & 0,82 \\
\hline Forecast $2015^{* *}$ & 4325 & 278 & 421 & 510 & 130 & 6475 \\
\hline R2015/P2015** \% & 0,83 & 0,71 & 0,83 & 1,04 & 1,22 & 0,85 \\
\hline
\end{tabular}

\section{Road traffic evolution during the 2015-2018}

source: CESTRIN

On the national roads of Romania there are currently 480 traffic counters, out of which 329 are of ISAF-MCSD type (totalizer), 70 are ADR 2000 (classifier) and 81 are type ADR3000 (WIM classifier), located, mainly, on European national roads and main roads.

After the analysis of the results of the automatic traffic records, it was found that the average daily average traffic increased by about 4.7\% in 2016 compared to 2015 (the last general circulation census), i.e. by about 1.4\% in 2017 compared to 2016, one of the reasons being the elimination of the tax car registration. Traffic continued to grow slightly by $0.2 \%$ compared to 2017, so traffic in 2018 increased by about $16 \%$ in 2015.

The evolution of road traffic, for the period 2011-2018, for the main vehicle classes, obtained by processing data from the classifier meter network, is presented in Table no. 4.

Table no. 4 Road traffic evolution during the 2011-2017 period across the national road network on classifier counters network

\begin{tabular}{|l|r|r|r|r|r|}
\hline & \multicolumn{1}{|c|}{ Cars } & \multicolumn{1}{c|}{ Trucks } & \multicolumn{1}{c|}{ TIR } & Buses & Total vehicles \\
\hline AADT 2011 & 6020 & 1258 & 783 & 79 & 8139 \\
\hline AADT 2012 & 5832 & 1244 & 808 & 84 & 7969 \\
\hline AADT 2013 & 6017 & 1181 & 726 & 75 & 7998 \\
\hline AADT 2014 & 6064 & 1238 & 776 & 79 & 8156 \\
\hline AADT 2015 & 6531 & 1352 & 834 & 86 & 8803 \\
\hline AADT 2016 & 7021 & 1418 & 840 & 91 & 9370 \\
\hline AADT 2017 & 7493 & 1510 & 888 & 97 & 9987 \\
\hline AADT 2018 & 7712 & 1538 & 862 & 91 & 10212 \\
\hline $\mathbf{2 0 1 6 / 2 0 1 5}$ & 1,08 & 1,05 & 1,01 & 1,06 & 1,06 \\
\hline $\mathbf{2 0 1 7 / 2 0 1 5}$ & 1,15 & 1,12 & 1,06 & 1,13 & 1,13 \\
\hline $\mathbf{2 0 1 8 / 2 0 1 5}$ & 1,18 & 1,14 & 1,03 & 1,06 & 1,16 \\
\hline
\end{tabular}


Between 2005 and 2018 road traffic on the national road network, according to the data obtained from the totalizers, registered an evolution presented in Figure no. 2.

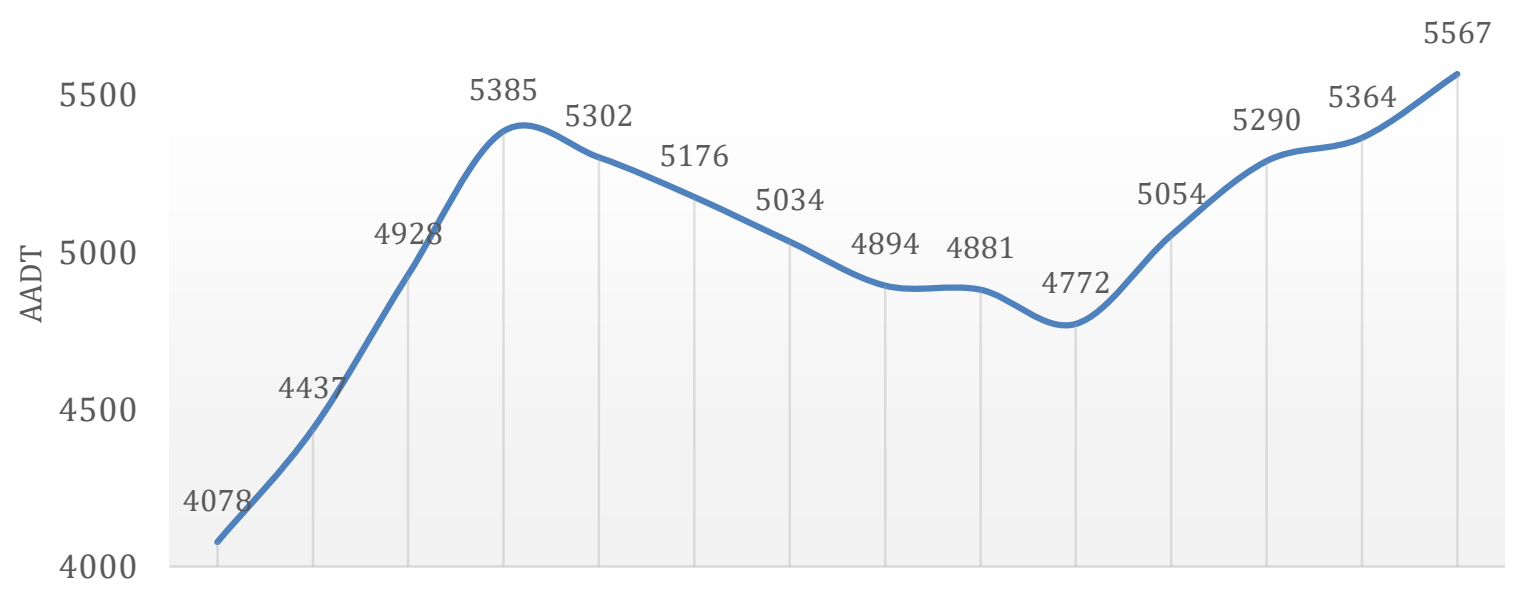

20052006200720082009201020112012201320142015201620172018

Figure no. 2 - AADT evolution in 2005-2017 period Automatic circulation records on the totalizators Source: CESTRIN

As an effect of the economic crisis in 2009-2010, road traffic on the national road network, for the period 2009-2014, has decreased considerably. As a result of this decrease, evolution coefficients were obtained for the period 2020-2025, showing a trend of decreasing road traffic.

From the data provided by automatic meters it is observed that the traffic registered a significant increase in 2016 as compared to 2015, the trend of growth continuing for the year 2017 and a slight increase also in 2018.

The graphs in figure no. 3 present a considerable difference between the traffic registered in the period 2016-2018 on the counters class and the traffic estimated according to the average evolution rate for the same period, compared to the census in 2015, except for the situation regarding the total vehicle category.

It can be seen that in the case of the total number of vehicles as well as in the case of cars, the values recorded by the meters are very close to the estimated values by using the optimistic variant. In contrast, in the case of trucks, the road traffic registered a real increase higher than the predicted variants. The evolution of traffic for TIRs and buses in the period 2015-2016 is close to the forecast based on the average. After 2016, the number of buses decreases compared to the projected average, while the number of TIRs increases, approaching the values of the optimistic variant. 


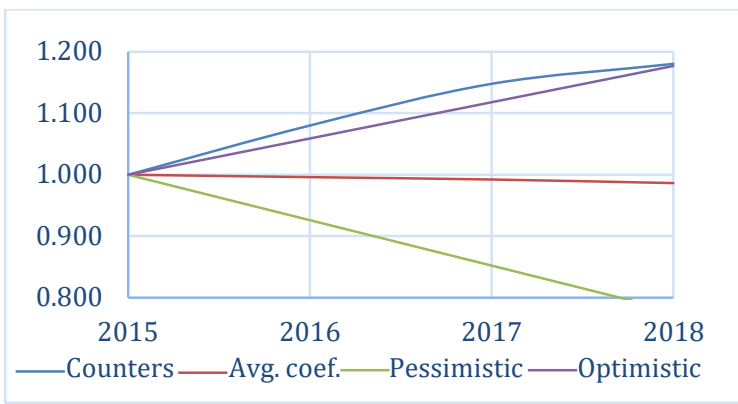

Cars

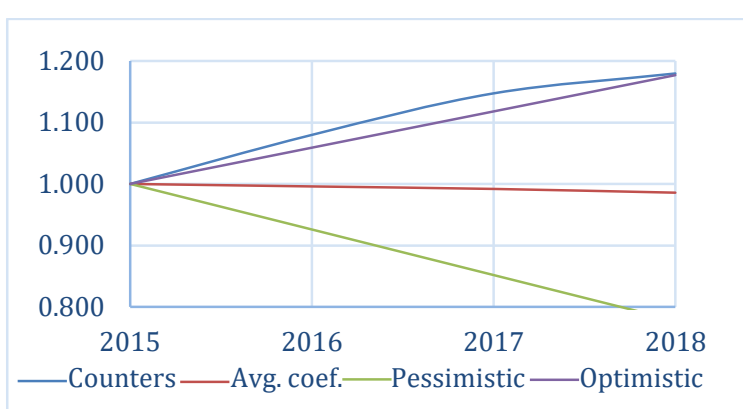

TIRs

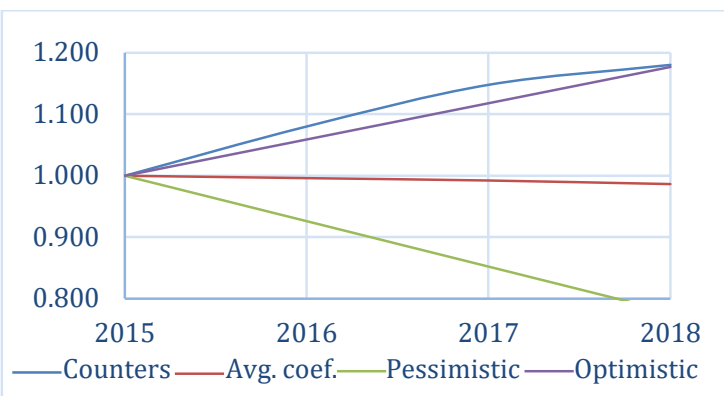

Trucks

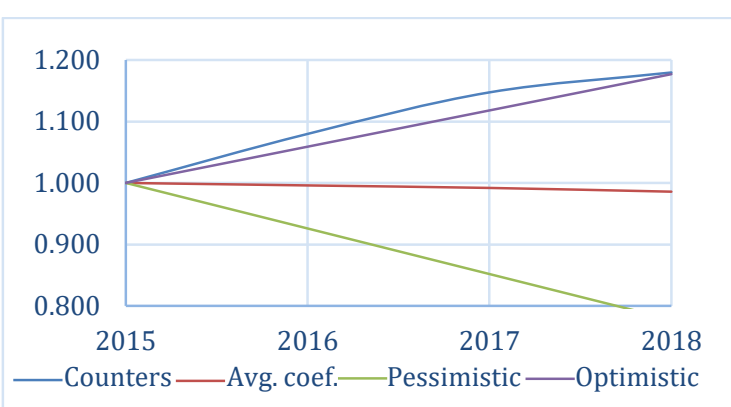

Buses

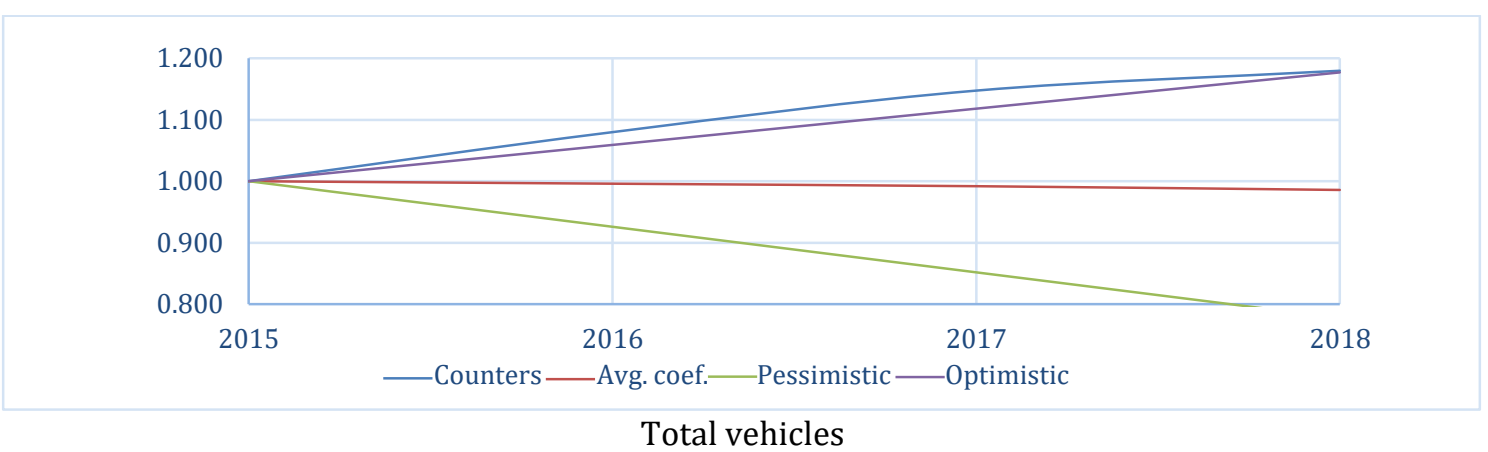

Figure no. 3 - Road traffic evolution 2016-2017 versus 2015, recorded and estimated Source: Authors' own research

\section{Methodology for elaboration of coefficients of evolution of road traffic on the national road network}

In order to determine the coefficients of evolution of road traffic for the period 2020-2040 several econometric models of simple and multiple regression were tested, Lagrange interpolations which underlie the construction of a combined forecasting methodology, which provided the best results.

The determination of the fleet of vehicles and their route for the 2020-2040 forecasting years was achieved through a simple linear regression function, taking into account the recorded GDP values for the period 1995-2015, as well as the predicted according to the National Prognosis Commission and the Master Plan for Transport for the period 2015-2040.

The calculation of the traffic evolution coefficients was achieved by an adapted version of the simple extrapolation function, which also took into account the forecasting coefficients of the fleet of vehicles and their route. 


\section{Estimation of the car fleet prognosis by the linear regression method}

The following linear regression model was used to estimate the mean value of the vehicle fleet (dependent variable) according to the projected values of GDP (independent variable): $\mathrm{y}_{i}=b_{0}+b_{1} \cdot x_{i}+\varepsilon_{i}$,

where:

- $b_{0}$ şi $b_{1}$ are the coefficients of the regression function;

- $\varepsilon_{i}$, residual value;

- $Y$, the cars fleet;

- $X$, GDP (mil. lei).

\begin{tabular}{|c|c|c|c|c|c|}
\hline \multicolumn{2}{|l|}{ SUMMARY OUTPUT } & & & & \\
\hline \multicolumn{2}{|c|}{ Regression Statistics } & & & & \\
\hline Multiple R & 0,9603 & & & & \\
\hline R Square & 0,9222 & & & & \\
\hline Adjusted R Square & 0,8963 & & & & \\
\hline Standard Error & 768342,4221 & & & & \\
\hline Observations & 5 & & & & \\
\hline \multicolumn{6}{|l|}{ ANOVA } \\
\hline & $d f$ & $S S$ & $M S$ & $F$ & Significance F \\
\hline Regression & 1 & $2,09902 \mathrm{E}+13$ & $2,09902 \mathrm{E}+13$ & 35,5556 & 0,0094 \\
\hline Residual & 3 & $1,77105 \mathrm{E}+12$ & $5,9035 E+11$ & & \\
\hline Total & 4 & $2,27613 \mathrm{E}+13$ & & & \\
\hline
\end{tabular}

\begin{tabular}{lrrrrrr}
\hline & Coefficients & \multicolumn{1}{c}{ Standard Error } & \multicolumn{1}{c}{ t Stat } & \multicolumn{1}{c}{$P$-value } & \multicolumn{1}{c}{ Lower 95\% } & Upper 95\% \\
\hline Intercept & 1485032,5420 & 690926,9953 & 2,1493 & 0,1208 & $-713805,5214$ & 3683870,6054 \\
GDP (mil. RON) & 38,5337 & 6,4623 & 5,9629 & 0,0094 & 17,9678 & 59,0996 \\
\hline
\end{tabular}

Figure no. 4 - Results of regression analysis source: CESTRIN

Following data processing, the following regression equation was obtained:

the cars fleet $=1485032,5420+38,5337 \cdot$ GDP

Based on the output (Figure no. 4) the following conclusions can be formulated:

- the model used is valid (Significance $F=0,0094$ );

- the $b_{1}$ coefficient of the model are statistically significant for a significance level of $5 \%$;

- the model explains $92.22 \%$ of the cars fleet variation;

- an increase in GDP of one million RON will result in an increase in the cars fleet of about 39 vehicles.

On the basis of the linear regression equation thus determined and the predicted values of GDP, the predicted values of the total vehicle fleet for the forecasting years 2020, 2030, 2035 and 2040 were calculated. The same procedure was also used to obtain the predicted values for each vehicle category.

Using the model and GDP forecast (CNSP) forecasts, the cars fleet forecasts for the above years are:

Table no. 5 Cars fleet evolution

\begin{tabular}{|c|c|c|}
\hline Year & GDP forecast (mil. RON) & Cars fleet forecasts \\
\hline $\mathbf{2 0 2 0}$ & $220.056,01$ & 9.964 .607 \\
\hline $\mathbf{2 0 2 5}$ & $250.650,83$ & 11.143 .539 \\
\hline $\mathbf{2 0 3 0}$ & $287.495,94$ & 12.563 .319 \\
\hline $\mathbf{2 0 3 5}$ & $324.341,06$ & 13.983 .098 \\
\hline $\mathbf{2 0 4 0}$ & $361.186,17$ & 15.402 .877 \\
\hline
\end{tabular}

Source: Authors' processing based on CNSP data 
Validation of the results obtained can be done only after traffic censuses made by CESTRIN.

It is worth mentioning that for the estimation of the optimistic and pessimistic variants, it was considered that the distribution of the predicted values for the park and the road follows a Gauss law, thus resulting the coefficients (optimistic and pessimistic).

Some disadvantages of the presented method must be highlighted:

- assessments do not provide a corresponding weight for the last year with the known achievements, which are the bridge between the past and the near future;

- the evaluations do not take into account the phenomenological influence of the factors of influence.

\section{Elaboration of road traffic forecast by the combined method of simple regression and interpolation}

Elaboration of the average forecast coefficients by categories of interurban public roads: national, county and communal and for the 11 vehicle groups taken into account in the 2015 census, in the three hypotheses of traffic evolution: minimal (pessimistic), medium (probable) and maximum (optimistic) required the following steps:

a) Analysis of the evolution of the car fleet and of the average annual vehicle mileage;

b) The forecast of the evolution of the traffic on the interurban public road network in the average evolution hypothesis, differentiated on the 11 category of vehicles taken into account at the 2015 census;

c) Differentiation of the traffic evolution forecast for the period $2015-2040$ by road categories;

d) Determination of the average annual rates of traffic evolution by category of vehicles and categories of interurban public roads.

e) Determination of the forecast of traffic evolution on the interurban public roads network in the minimum and maximum assumptions for the period 2015-2040.

The entire activity of elaborating these evolution coefficients was based on the following calculation assumptions:

- 3.92\% average GDP growth over the period 2021-2030;

- 3.45\% average GDP growth over the period 2031-2040.

The coefficients of the evolution of traffic by categories of public roads and vehicle groups for the period 2015-2040 were determined using the relationship:

$C_{i j}^{D}=C_{i j}^{T}\left(\begin{array}{l}\frac{N_{i, 2015}^{D}}{N_{i, 2010}^{D}} / \\ / \frac{N_{i, 2015}^{T}}{N_{i, 2010}^{T}}\end{array}\right)$

where:

- $C_{i j}^{D}$ - traffic evolution coefficient for road category $D$, vehicle group and predicted year $j$;

- $C_{i j}^{T}$ - traffic evolution coefficient on the whole public road network $T$ for the vehicle group and forecast year $j$;

$-\frac{N_{i, 2015}^{D}}{N_{i, 2010}^{D}}$ - the evolution of traffic in 2010-2015 on the D road category and category $i$ of vehicles; 
$-\frac{N_{i, 2015}^{T}}{N_{i, 2010}^{T}}$ - the evolution of traffic on the whole network of roads and $i$ vehicle category in 2010-2015.

Differentiation of traffic forecasting by categories of roads, taking into account the evolution of traffic by groups of vehicles, by categories of public roads, was made on the basis of traffic forecast for the public road network.

\section{Conclusions}

Transport networks are important both at national and international level, and can easily state that they are an essential contribution to the development of the European economy. To prosper, Europe needs a good connection infrastructure based on a strong European transport network in the EU countries and interstate. With the 2050 deadline for completion, besides safer traffic and a lower impact on the climate, the overall goal of the central network is to decongest and streamline traffic so that most companies are at within a maximum of 30 minutes. Obviously, this also extends to citizens. In Romania there will be two corridors of the central network, and this should be completed by the end of 2030 .

The methodology is incomplete with regard to the development of detailed evolution coefficients by category of road and vehicle class, which may lead to relatively inadequate assessments of road design in terms of road capacity and load capacity.

The use of these coefficients is relatively limited, only for general analysis of the evolution of road traffic on the national road network, because it provides credible future data only at the level of total vehicles on the national road network, without differentiating by category of roads.

Consequently, in order to provide road and motorway designers with the most appropriate forecasts regarding the development of road traffic on public road networks, it is necessary to develop a complex methodology based on a number of well-defined indicators and using econometric tools effective.

\section{References}

TEN-CONECT. (2009). Traffic flow: Scenario, Traffic Forecast and Analysis of Traffic on the TEN-T, Taking into Consideration the External Dimension of the Union - Final Report. CESTRIN, 2016, Rezultatele prelucrării înregistrărilor de la recensământul circulației rutiere din anul 2010 sii 2015.

CESTRIN, 2016, Rezultatele prelucrării înregistrărilor de la rețeaua de contori de trafic din perioada 2010 - 2017.

Commission of the European Communities, Directorate-General for Transport. (1993). Trans-European Networks. Towards a Master Plan for the Road Network and Road Traffic?, Motorway Working Group Report, Brussels, Luxembourg. ISBN 92-8264881-8

http://aei.pitt.edu/39803/1/A4167.pdf

CNSP. (2018). Studiu de fundamentare Autostrada Târgu Neamț - Iași

CNSP. (2018). Studiu de fundamentare Autostrada Ploiești - Brașov

Davis, G. A., \& Nihan, N. L. (1991). Nonparametric regression and short-term freeway traffic forecasting. Journal of Transportation Engineering, 117(2), 178-188.

https://doi.org/10.1061/(ASCE)0733-947X(1991)117:2(178)

Dolombyan A.V., Kocherga E.V., Semchugova E., Negrov N. (2017). Traffic forecasting model for a road section. Transportation Research Procedia, 20, 159-165 
https://doi.org/10.1016/j.trpro.2017.01.040.

Manea, I.D., (2016), Statistică Aplicată, Meteor Press, București.

OECD. (2013). Road and motorway networks, in Sectoral trends of environmental significance, OECD Publishing, Paris,

https://doi.org/10.1787/9789264208919-table61-en.

Oswald, R. K., Scherer, W. T., \& Smith, B. L. (2000). Traffic flow forecasting using approximate nearest neighbor nonparametric regression.

Ripley, B. D., (1999). Pattern recognition and neural networks. United Kingdom: Cambridge University Press.

Pupavac, D. (2014). Econometric Model For Forecasting Traffic On Croatian Motorways, Interdisciplinary Management Research, Josip Juraj Strossmayer University of Osijek, Faculty of Economics, Croatia, vol. 10, pages 891-900.

Taylor, B. D., Miller, D., Iseki, H., \& Fink, C. (2003). Analyzing the determinants of transit ridership using a two-stage least squares regression on a national sample of urbanized areas.

https://escholarship.org/uc/item/7xf3q4vh

Tițan, E., (2002), Statistică. Teorie și aplicații în sectorul terțiar, Editura Meteor Press, Bucuresti.

Wisconsin Department of Transportation. (2012). Transportation Planning Manual

$* * *$ http://www.insse.ro/cms/

*** http://www.cnp.ro/ 